\title{
Erosão diferencial e propriedades geomorfológicas das rochas - exemplos do NE Brasileiro
}

\author{
Differential erosion and geomorphological rocks properties - examples from Brazilian \\ Northeast
}

MAIA $^{1}$, R. P.; CASTRO ${ }^{2}$, H. S.

rubsonpinheiro@yahoo.com.br

\begin{abstract}
Resumo
Vários condicionantes litológicos e estruturais influenciam os processos de erosão diferencial do embasamento. No Nordeste Brasileiro é possível identificar muitos exemplos onde a erosão têm distinguido formas de relevo segundo seus controles lito-estruturais. Esses controles são representados principalmente pelo grau de faturamento, pela litologia/faciologia e pelos planos de foliação ígnea, metamórfica e de acamamento, nos terrenos sedimentares. O presente artigo fará uma análise de diferentes padrões de relevo que se desenvolvem em tipos litológicos distintos ou em uma mesma unidade litológica a partir da correlação de fácies. Nesse sentido, a manutenção de topografias elevadas no embasamento resulta da menor erosão em núcleos de resistência mecânica aos processos denudacionais. Essa resistência se deve sobretudo as características litológicas, faciológicas, petrográficas e estruturais que se somam para aumentar ou diminuir a coesão físicoquímica da rocha frente à meteorização.

Palavras chave: erosão diferencial, litologia, estrutura, relevo, Nordeste Brasileiro.
\end{abstract}

Abstract

\begin{abstract}
Various lithological and structural conditions influence the processes of basement differential erosion. It's possible to identify in Brazilian Northeast several examples where erosion has distinguished relief shapes according to its litho-structural controls. These controls are represented mainly by the lithology/faciology and by the igneous foliation plans, metamorphic and lodging at the sedimentary terrain. This article will analyze different relief patterns that develop in distinct lithological types or on a lithological unity from facies correlation. Given this, the maintenance of high topographies in the basement results from the lowest erosion on mechanical resistance cores to denudation processes. This resistance occurs mainly due to the lithological, faciological, petrographical and structural features, that add up to increase or decrease the physicochemical cohesion of the rock facing the weathering.
\end{abstract}

Keywords: differential erosion, lithology, structure, relief.

\section{INTRODUÇÃO}

Nas superfícies erosivas a supremacia do fator exógeno na elaboração do relevo tem sua melhor expressão nas formas dissecadas. Contudo a dissecação em muitos casos é diretamente condicionada pela disposição morfoestrutural. Assim os processos de denudação da crosta continental na margem setentrional do Nordeste Brasileiro têm distinguido formas residuais a partir da erosão diferencial (MAIA et al., 2015).

No Nordeste brasileiro o embasamento é composto por amálgamas de litologias diversas herdadas de uma história geotectônica policíclica, com índices de dissecação variados, onde muitas ${ }^{I}$ Rubson Pinheiro Maia, Departamento de Geografia, Universidade Federal do Ceará, Fortaleza-CE, Brasil. 
ocorrências de cristas residuais são correlatas a litologias mais resistentes ao intemperismo, e as depressões a litologias menos resistentes. Contudo, apenas a diferenciação litológica não é suficiente para justificar o cenário atual do relevo, pois é comum a superimposição da drenagem sobre as cristas que estão resistindo na topografia por erosão diferencial. Também e comum em uma mesma unidade litológica a formação de maciços e depressões. Neste interim, é importante destacar a influencia da cinemática estrutural no condicionamento do padrão de denudação das morfoestruturas modeladas por processo denudacionais cenozoicos.

Nessa perspectiva, o presente artigo, propõe uma analise acerca do condicionamento litoestrutural sobre os processos erosivos e denudacionais. Tal análise basear-se-á na configuração do modelado em escala regional e local, enfatizando a relação entre forma, estrutura e litologia.

\subsection{Localização e caracterização da área}

A área de estudo deste trabalho compreende o setor setentrional do Nordeste do Brasil, compondo o domínio oriental do maciço da Borborema. Esta área é caracterizada por relevos desenvolvidos em litotipos variados, com destaque para as bacias paleozoicas e mesozoicas, os maciços cristalinos e as depressões sertanejas, todos em sua maioria com padrões de dissecação orientados segundo as direções das principais zonas de cisalhamento transcorrentes (Figura 1). As altitudes variam de 0 a 200m na faixa costeira aumentando suas amplitudes em direção ao interior, onde podem ultrapassar os $1.000 \mathrm{~m}$ no topo dos maciços mais elevados. 


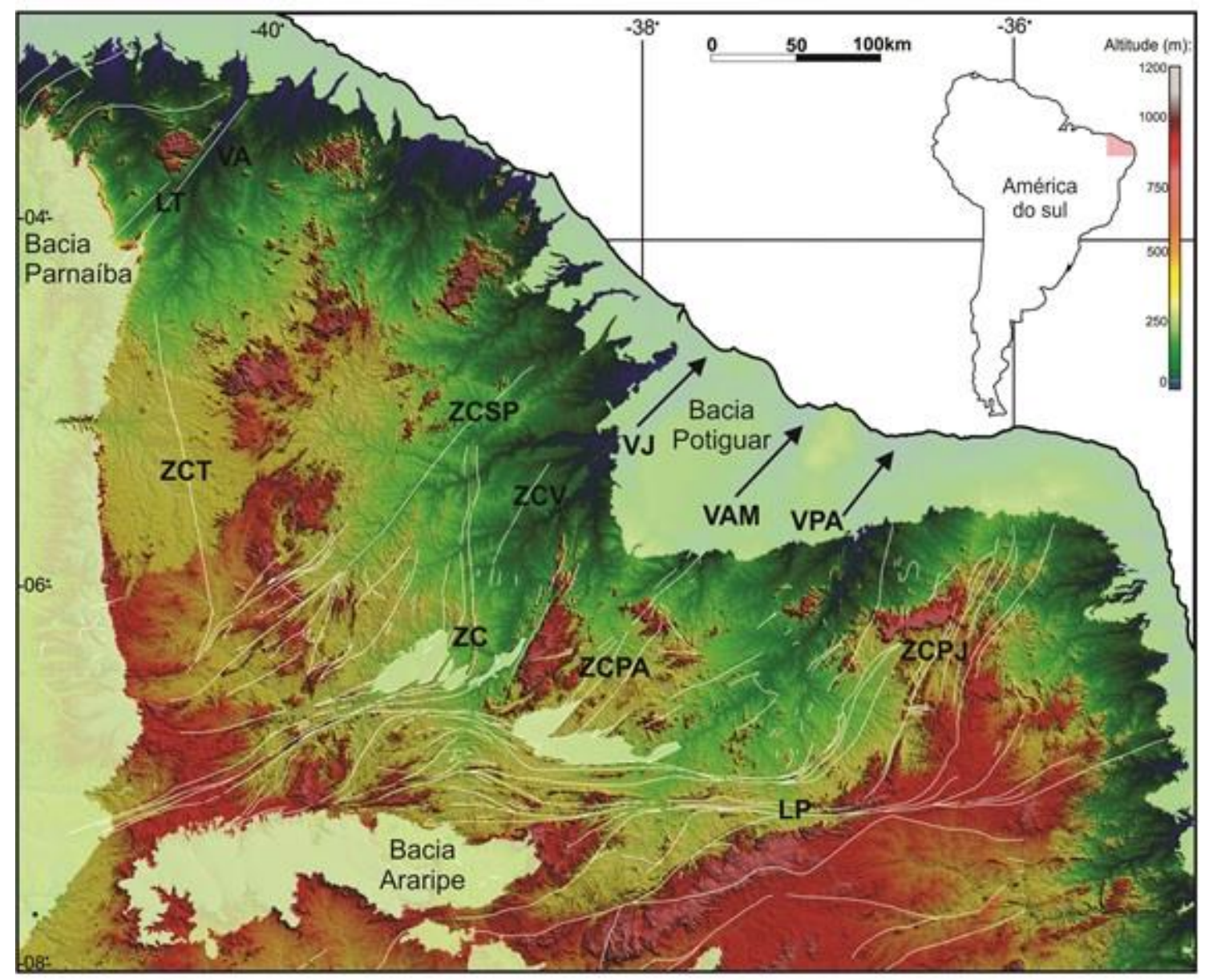

Figura 01: Geomorfologia (SRTM) e estruturas (Lineamentos estruturais) do NE setentrional Brasileiro. LT: Lineamento Transbrasiliano, ZCT: Zona de Cisalhamento de Tauá, ZCSP: Senador Pompeu, ZCV: Jaguaribe, ZC: Orós, ZCPA: Portalegre, ZCPJ: Picuí-João Câmara, LP: Lineamento Patos, VJ: Vale do Rio Jaguaribe, VAM: Vale do Rio Apodi-Mossoró, VPA: Vale do Rio Piranhas-Açu (Fonte: Maia e Bezerra, 2014).

\section{METODOLOGIA}

Nesse trabalho, foram correlacionadas diferentes formas de relevo, padrões, densidade e ocorrência às unidades litológicas/faciológicas e estruturais das rochas onde ocorrem. Os mapas de geologia da CPRM (CAVALCANTE et al., 2003; ANGELIM et al.,2006; GOMES et al, 2001; WANDERLEY et al, 2002) com os dados de SRTM 30m (Shuttle Radar Topography Mission), descrições petrográficas (NOGUEIRA, 2004; ALMEIDA, 1995; MAGINI, C \& HACKSPACHER P.C., 2008 BRANDÃO,1995 e outros) nos permitiram fazer a correlação entre as feições de relevo e seus condicionantes litológicos. Para tanto, foram realizados diferentes trabalhos de campo onde 
foram coletados informações acerca da petrografia macroscópica das rochas e as formas de relevo correspondentes.

Esse trabalho contou ainda com o Processamento Digital de Imagens a partir de composições coloridas por meio das bandas espectrais do Sensor TM - Landsat 5. Essas composições permitiram estabelecer conexões entre geomorfologia, controle estrutural, e litológico. Os blocos diagramas deram suporte a interpretação geomorfológica e a representação tridimensional acerca da evolução do relevo e foram desenvolvidos em software de desenho e a mão livre.

\section{RESULTADOS}

O controle estrutural sobre os processos de dissecação ocorrem ao longo de estruturas deformacionais dúcteis e rúpteis impressas no embasamento cristalino pré-cambriano. Essas estruturas são representadas por um conjunto de morfologias desenvolvidas em zonas de deformação herdadas da estruturação pré-cambriana e podem ser constatadas no relevo em diferentes escalas de grandeza.

\subsection{Controles Morfoestruturais de Macroescala}

Os controles estruturais de macroescala ocorrem, sobretudo ao longo das zonas de deformação, onde os efeitos da granitogênese brasiliana e consequentemente do metamorfismo associado possibilitaram o desenvolvimento de cristas a partir da erosão diferencial.

$\mathrm{Na}$ Província Borborema, extensas zonas de cisalhamento transcorrentes brasilianas a seccionam nas direções E-W e NE, zonas estas que, em geral controlaram o alojamento de diversos corpos granitoides (Nascimento, 1998), além disso, controla o relevo, que é comumente disposto em sequencias de cristas e vales orientados segundos os trends de lineamentos. Esses trends são representados por planos de foliação, por cristas quartizíticas ou de micaxistos, por intrusões graníticas e por planos de milonitização. Assim originam-se lineamentos paralelos de resistências diferenciadas a denudação geoquímica ou física favorecendo através da erosão diferencial o desgaste das faixas menos tenras segundo os planos de deformação e a manutenção dos corpos intrusivos, que passam a ser expressos no relevo como cristas residuais de origem estrutural.

O resultado final da atuação da erosão é o desaparecimento do relevo e o retorno da crosta a sua espessura inicial, anterior ao evento deformacional. Isso implica entre outras coisas, em que o substrato de subsuperfície, aparecerá em superfície. Dessa forma a erosão de zonas de cisalhamento 
dúcteis pré-cambrianas conduz a progressiva exumação de maciços cristalinos, descritos tradicionalmente como residuais. Essa exumação possibilitou através da erosão diferencial a formação de trends de lineamentos geomorfológicos dispostos em formas lineares positivas e negativas associadas aos planos de deformação brasiliana (Fig. 2).

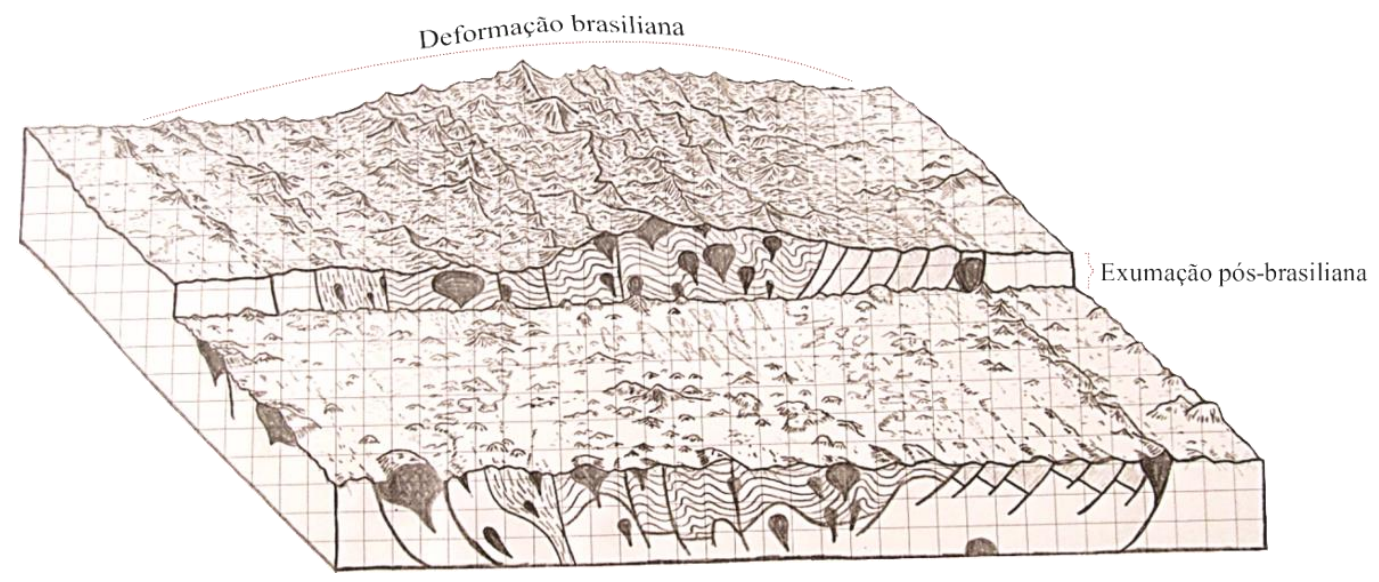

Figura 02: Exumação nas zonas de cisalhamento evidencia as estruturas deformacionais de caráter dúctil de idade brasiliana.

Dessa forma, os planos de deformação brasiliana condicionam em escala regional diversas morfologias, principalmente aquelas associadas às zonas de cisalhamento dúcteis onde o relevo é caracterizado por cristas simétricas com vertentes de declividade acentuadas dispostas de forma contínua (Maia e Bezerra, 2013). São exemplos dessa contextualização o setor NW da área de estudo, correspondente ao domínio Transbrasiliano, o trend cariri-potiguar, a zona do domínio transversal e o setor setentrional do maciço da Borborema.

Segundo a figura 03 no setor setentrional da Província Borborema os quadrantes B, C, D e E constituem expressivos exemplos dessa configuração morfoestrutural, disposta em alinhamento de cristas residuais que confinam a drenagem de $1^{\circ}$ ordem e orientam a dissecação. No quadrante B, área correspondente à depressão periférica ocidental do Glint da Ibiapaba, o Lineamento Transbrasiliano controla o canal do Rio Jaibaras e parte do Rio Acaraú. Nesse setor, enquanto o Lineamento Transbrasiliano é responsável pelo deslocamento do front da escarpa do Glint da Ibiapaba, na depressão periférica sua influencia se dá sobre a dissecação fluvial que originou um vale orientado na direção NE-SW. Nas áreas correspondentes ao Maciço do Pereiro e entorno do Planalto de Santana o relevo é controlado estruturalmente pelas ZC (Zona de cisalhamento) Portalegre e Picuí - João Câmara. A exumação das ZC associada a esses setores resultou na formação de cristas e vales incisos de direção NE-SW que controlam os canais de escoamento do alto curso da bacia hidrográfica do rio Apodi-Mossoró e as pequenas bacias que dissecam os 
segmentos N e NE do Maciço da Borborema. Essa disposição morfoestrutural resguarda em suas formas importantes indicadores de tectonismo. Esses Indicadores associados aos dados de natureza geocronológica (Datação por Luminescência), geológica (Deformações sin e pós deposicionais) e tectônica como falhas e sua sismicidade associada, tem subsidiado os estudos de Neotectônica e suas repercussões no relevo do Nordeste brasileiro. 

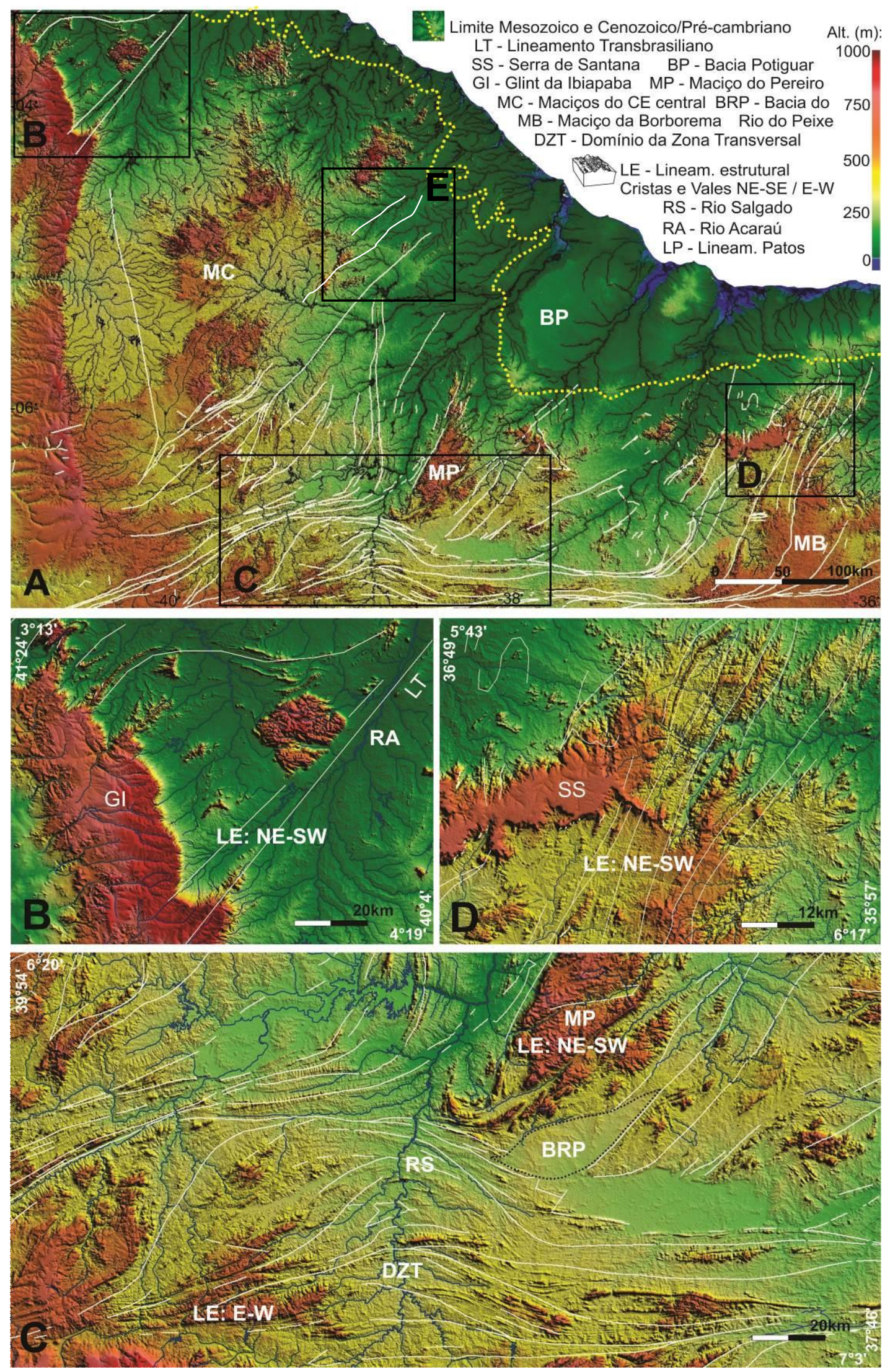
Figura 03: A-Geomorfologia do Nordeste setentrional brasileiro com ênfase no controle exercido pelas zonas de cisalhamento dúcteis Pré-cambrianas. B-Lineamento Transbrasiliano. C-Principais trends paralelos a Zona de Cisalhamento de Patos e Portalegre. D-Z.C. Picuí-João Câmara. E-Z.C. Orós e Senador Pompeu.

Mais ao sul, na área do lineamento Patos, correspondente ao domínio da zona transversal. Nessa área, o recuo das escarpas do maciço da Borborema foi responsável pela extensa denudação que evidenciou a sequencia de cristas E-W que se distribuem por uma faixa de aproximadamente $60 \mathrm{~km}$ de largura por mais de $500 \mathrm{~km}$ de extensão. Entre os domínios dessas cristas E-W e o maciço do Pereiro, ocorrem zonas de abatimentos tectônicos relacionados à reativação cretácea. Atualmente essas zonas compõem as bacias interiores do Nordeste Brasileiro.

No quadrante "E" os quartzitos tectônicos na zona de cisalhamento transcorrente dextral Orós (Cavalcante et al., 2003), formam cristas alongadas na Serra do Felix que é o divisor d'água da bacia do rio Piranji e, o rio de primeira ordem da mesma, é condicionando pela zona de cisalhamento transcorrente dextral Senador Pompeu. Essas zonas de falhas parecem também influenciar o contato entre os depósitos sedimentares, da formação Barreiras, do cenozoico, sobre o cristalino do pré-cambriano.

\subsection{Controles Litoestruturais de Mesoescala}

Os planos de foliação ao longo das zonas de deformação orientam a dissecação segundo a orientação estrutural do embasamento. Nessas áreas, os relevos ocorrem principalmente na forma de cristas alinhadas e resultam da erosão diferencial em quartzitos, gnaisses, granitos e migmatitos. A textura dessas litologias, principalmente quando afaníticas sustentam formas residuais em virtude de sua maior resistência a meteorizacão. Embora a foliação metamórfica ou magmática seja em si, uma condição que facilita a propagação de fraturas ao longo dos planos de lineação, o incipiente desenvolvimento dos cristais lhe confere maior resistência em virtude dos efeitos diminutos da expansão e contração térmica. Dessa forma, em termos gerais, rochas ou fácies cristalinas de textura porfirítica parecem sofrer com mais intensidade os efeitos da delaminação crustal quando comparadas com as rochas ou fácies de textura afanítica (Figura 04). Dessa forma, entre limites de unidades litológicas distinguidas em termos texturais, é comum o desenvolvimento de escarpas, normalmente orientadas segundo os planos de deformação ao longo de zonas de cisalhamento. 


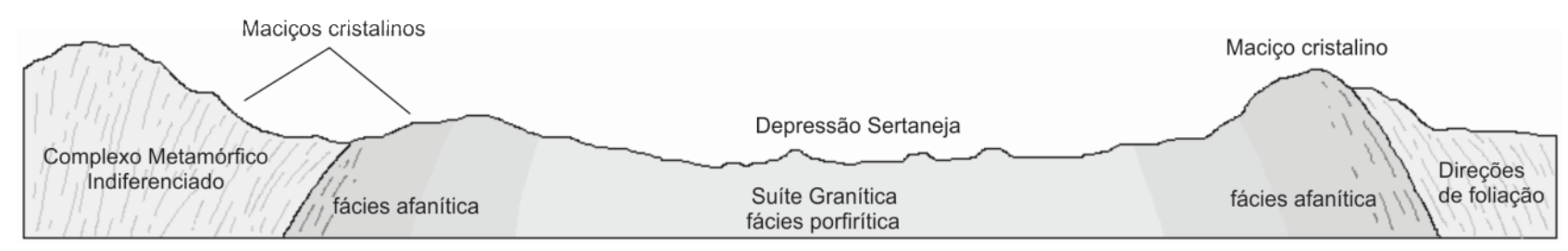

Figura 04: Perfil esquemático: Litologia e Topografia em área de intrusão granítica.

Nas áreas dos plutons graníticos, o processo de baloneamento e consolidação do pluton pode resultar na formação de diferentes fácies graníticas em uma mesma unidade litológica. A interação com a rocha hospedeira e o resfriamento desigual do batólito pode gerar no interior de uma unidade litológica diferenças texturais que terão grande relevância no condicionamento da erosão diferencial. Nessa perspectiva é possível perceber em diferentes plutons graníticos exumados, a ocorrência de relevos mais elevados em suas bordas e uma topografia mais rebaixada em sua porção central.

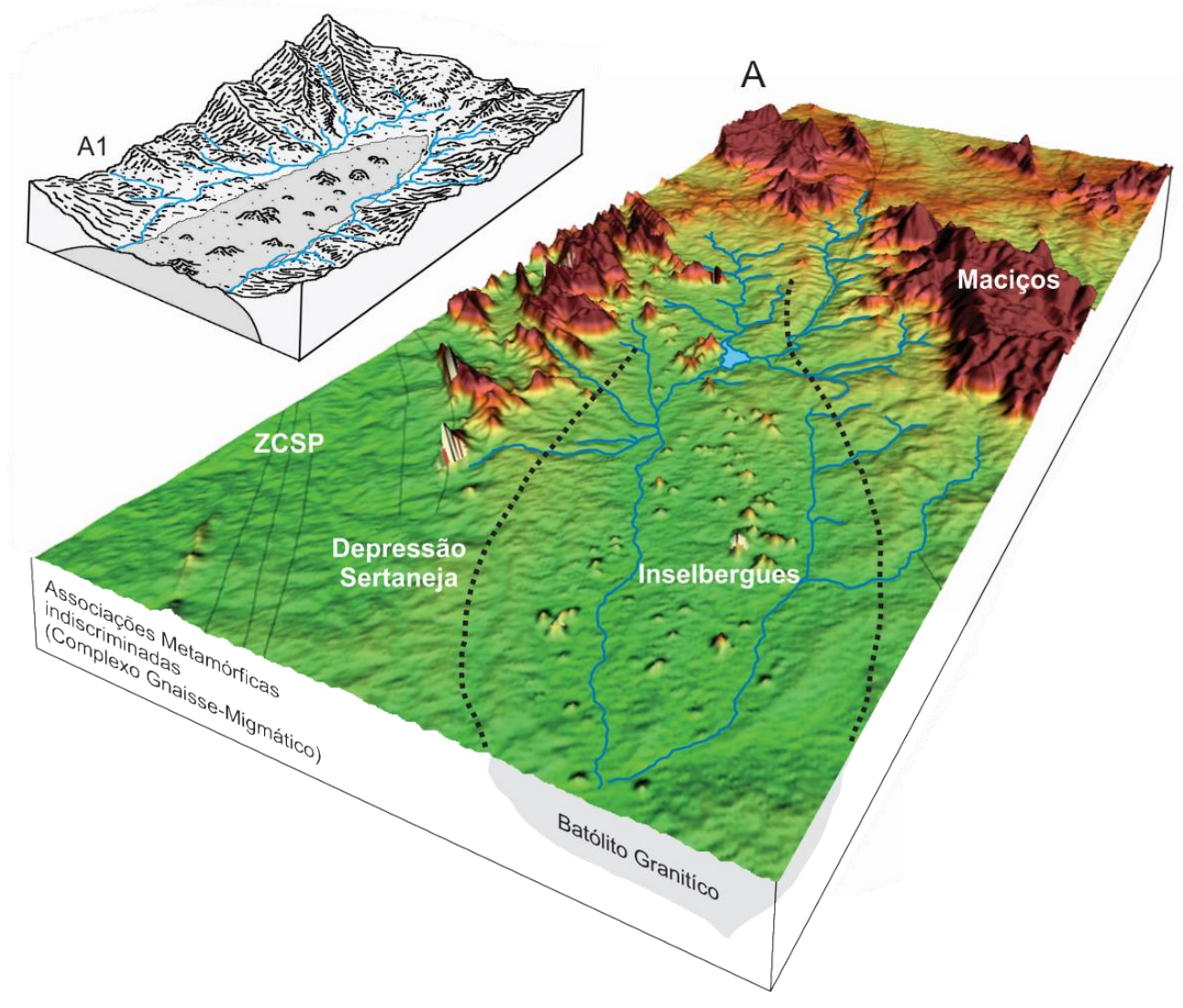

Figura 05: Campo de inselbergues circundados por maciços residuais em Quixadá- CE.

Essas diferenças topográficas podem ter sua explicação associada a diferença textural entre as bordas e a parte central do batólito exumado. Dessa forma os processos de erosão diferencial ao 
longo de plutons alojados entre zonas de cisalhamento, individualizam as fáceis graníticas segundo suas características estruturais. Essas características são representadas principalmente pelos planos de foliação ígnea e pela textura, associadas à organização estrutural dos falhamentos, pois os mesmos exercem importante condicionamento na intensidade da exumação dos terrenos e formação dos relevos.

\subsection{Controles Litoestruturais de Microescala}

Em escala local, as variações faciológicas dentro de uma mesma unidade litológica são as que possuem a melhor expressão no relevo. Em muitos relevos graníticos a feição de dissolução que os modelam deve-se à sua composição. Neste caso a solubilidade da biotita especificamente nos enclaves máficos e dos fenocristais de Feldspato. O menor teor de biotita associado a esses casos confere uma maior coesão física da rocha a intemperização termoclástica. Desse modo, nas escarpas de relevos graníticos que apresentam variação faciológica, desenvolve-se uma densa rede de dissecação representada por feições de dissolução tipo caneluras contínuas ou intercalada por níveis escalonados de bacias de dissolução do tipo gnammas. O ponto de partida para a formação de feições de dissolução são os enclaves máficos associados aos granitos (MAIA et al., 2015). Nesses enclaves ocorre um aumento pontual na proporção de biotita em relação ao feldspato resultando em uma dissecação mais intensa que encaixa a rede de drenagem originando a canelura.

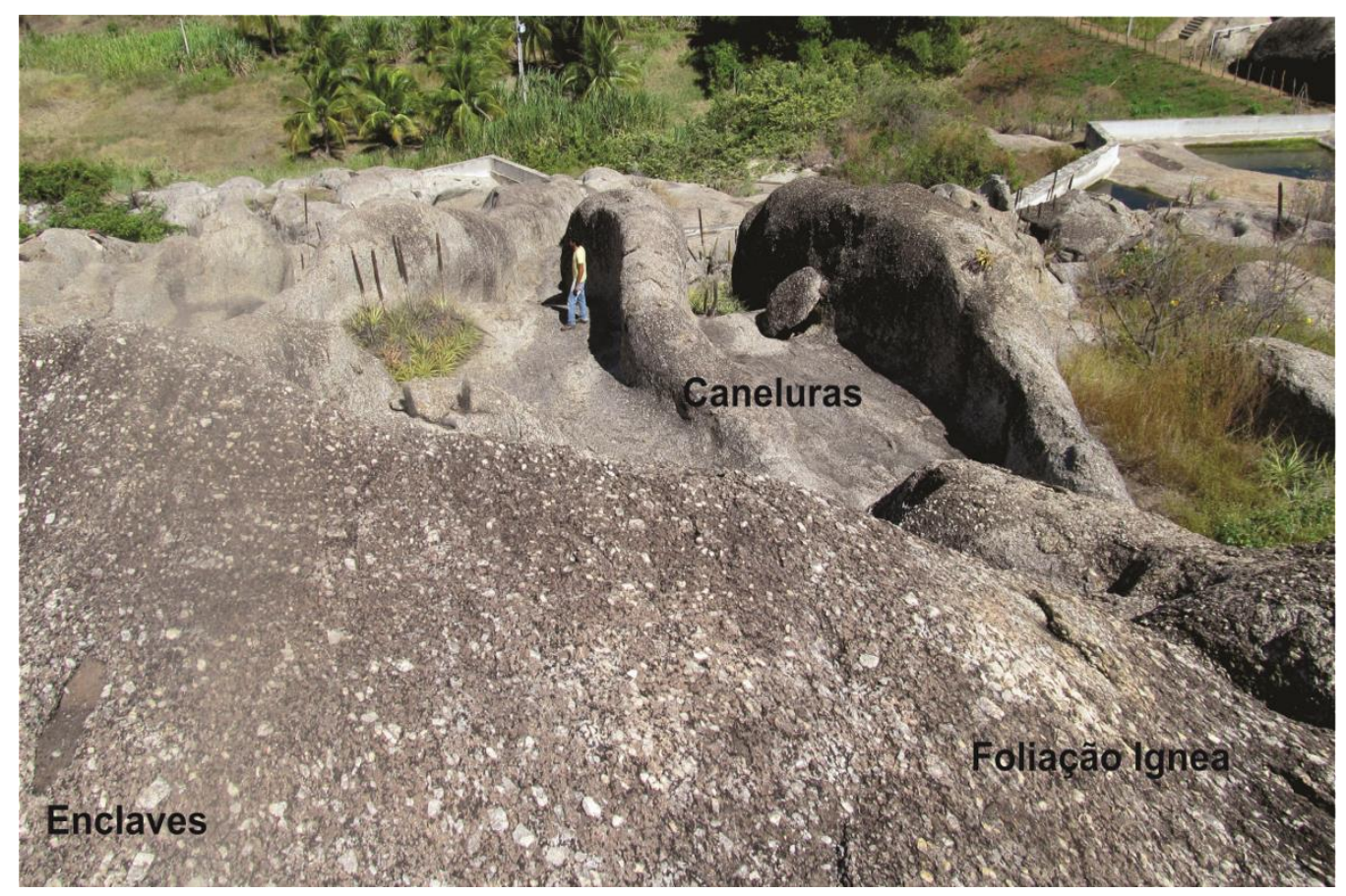

Figura 06: Inselbergs com feição de dissolução, no município de Quixadá, CE. 
Outras feições de erosão diferencial são igualmente importantes nas áreas sedimentares. Nesses casos o empilhamento vertical das camadas constitui o principal condicionante da erosão diferencial. Em camadas sedimentares, as variações texturais das rochas podem conferir níveis de resistência diferenciados. A erosão que se processa das camadas ou fácies de textura mais fina remove mais volume de rocha que nas rochas de textura mais grossa. Como resultado, muitas escarpas sedimentares mostram níveis recuados e níveis projetados em um padrão repetitivo que constitui em si, as variações de energia relativas ao ambiente deposicional.

Nas planícies litorâneas as falésias constituem um bom exemplo desse contexto. Moldadas em rochas da Formação Barreiras e Pós-barreiras, as variações nos níveis de energias relativas ao ambiente deposicional estão bem marcados no empilhamento vertical das camadas. Os níveis relativos a depósitos provenientes de ambientes transicionais e marinhos raso são mais recuados que depósitos siliciclasticos provenientes principalmente do ambiente fluvial e por vezes eólico. Essa variação faciológica dentro de uma mesma unidade litológica individualiza os ambientes deposicionais criando abrigos horizontais ao longo das camadas de textura mais fina.

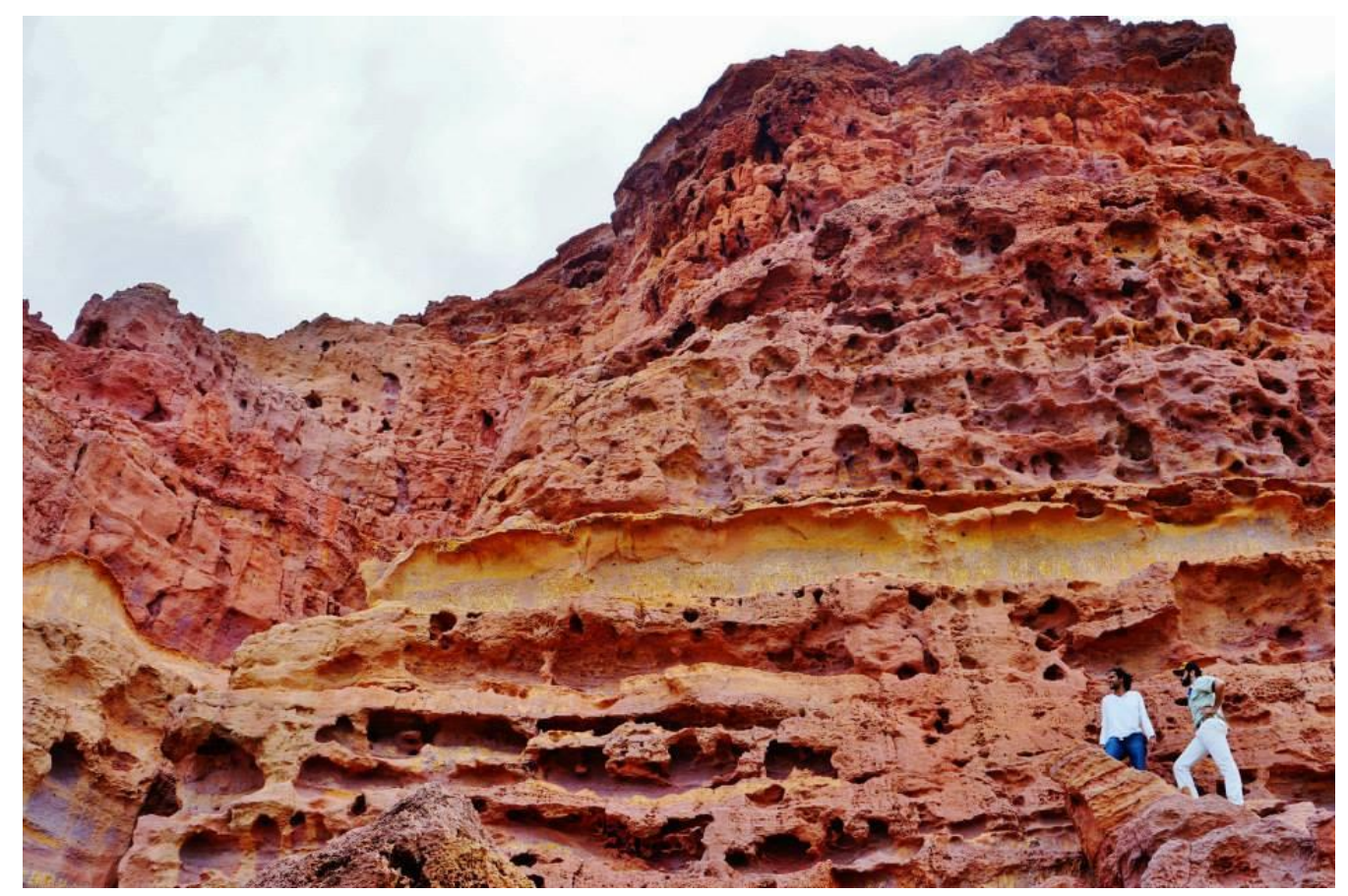

Figura 07: Tafonis de parede contínuos e honeycomb em arenitos da Formação Barreiras, nas falésias ao norte de Serra do Mel, município de Areia Branca, RN.

No ambiente Cárstico, os carbonatos Turonianos da Formação Jandaíra também constituem um bom exemplo os efeitos da meteorização seletiva das fácies do calcário. As variações de energia 
típicas do ambiente transicional para marinho raso refletem diretamente na granulometria das fácies. Isso resulta na formação de fácies de menor e maior calibre empilhadas em um padrão repetitivo.

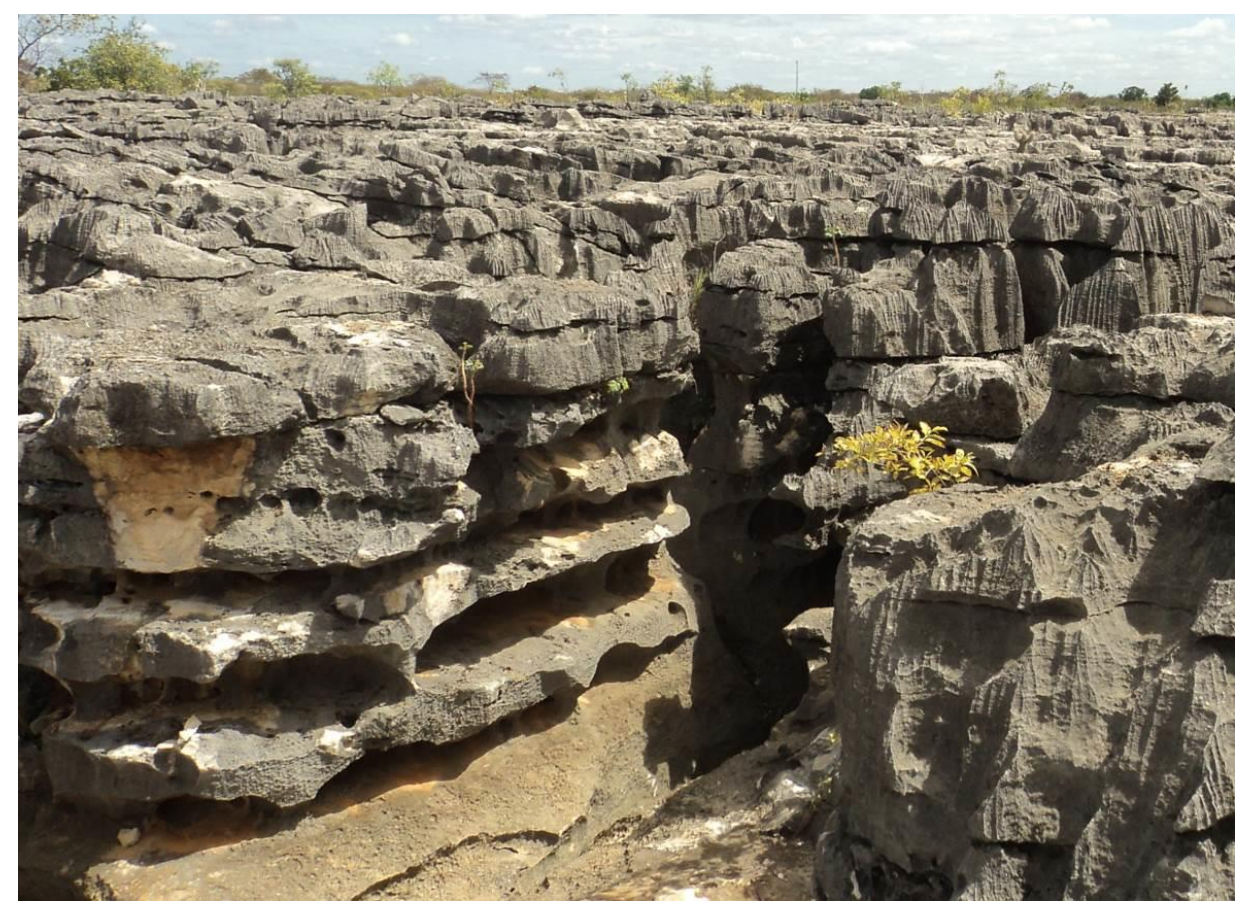

Figura 08: Controle faciológico na erosão diferencial do carste de Soledade no município de Apodi, RN.

Nas fácies mais finas os processos erosivos são mais intensos e resultam no maior recuo resultando na formação de abrigos. Nesses casos a maior erosão de uma determina fácies pode fazer colapsar as fácies superiores dando origem às dolinas de colapso. 


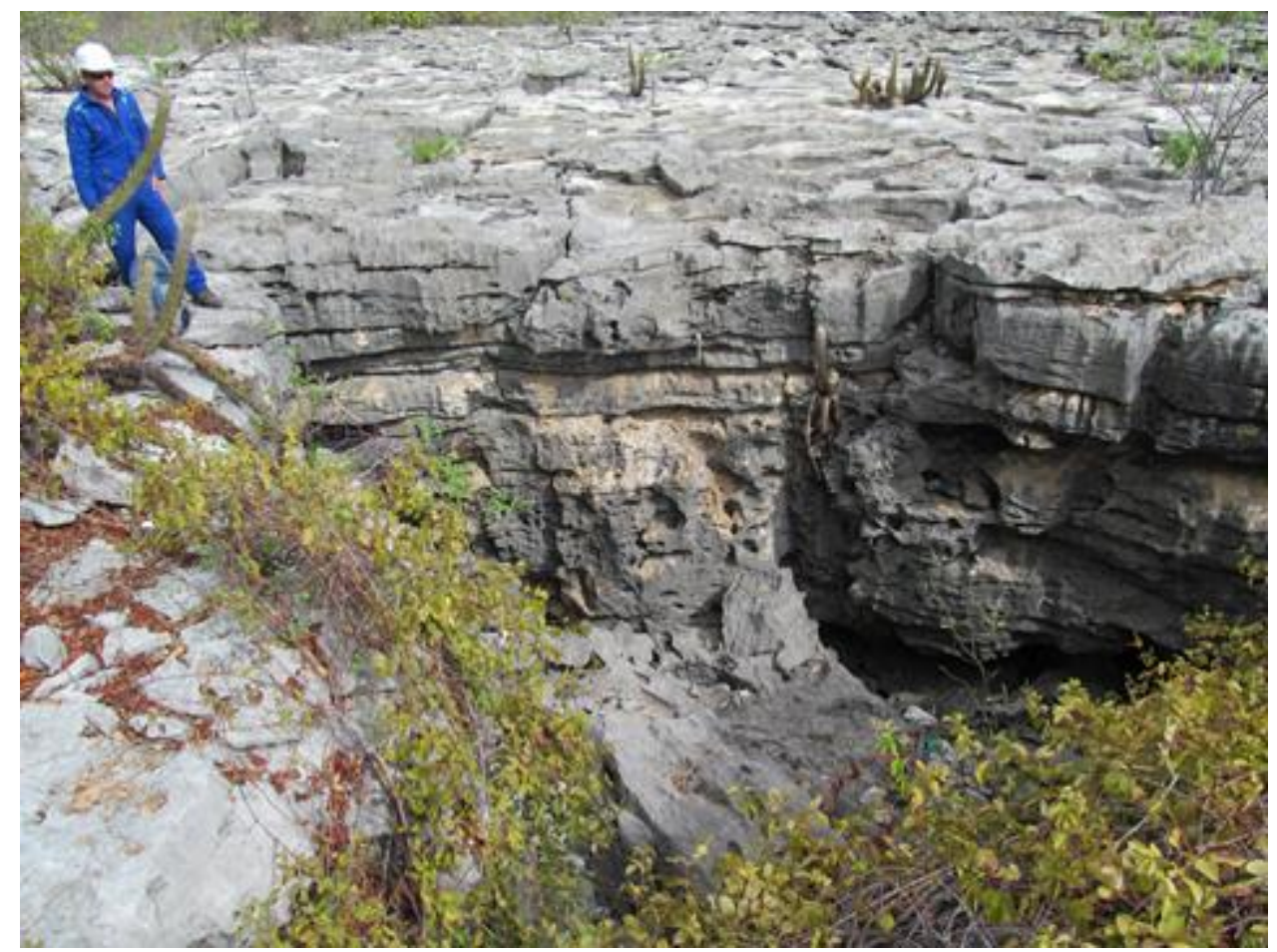

Figura 09: Dolina de colapso desenvolvida na Formação Jandaíra em Felipe Guerra - RN.

\section{CONCLUSÕES}

A erosão diferencial que se processa sobre o embasamento é diretamente condicionada por aspectos litológicos e estruturais. Nesse sentido, os trends de fraturas, os planos de foliação aumentam a susceptibilidade da rocha ao fraturamento termoclástico acelerando a saprolitização. Essa distribuição diferencial dos trends de lineamentos associados ao quadro de variabilidade climática imprimiu fases pedogênicas acompanhadas de fases erosivas. Essa variabilidade possibilitou a progressiva exumação dos núcleos granitoides menos fraturados originando assim muitos dos maciços do Nordeste semiárido brasileiro. As feições erosionais que os modelam podem ter sua gênese associadas à variabilidade faciológica e textural das unidades litológicas em que ocorrem.

\section{REFERÊNCIAS}

ALMEIDA, A. R. Petrologia e aspectos tectônicos do Complexo Granítico Quixadá -

Quixeramobim-CE. 1995. Tese (Doutorado) - Instituto de Geociências, Universidade de São Paulo, São Paulo, 1995. 
Angelim, L.A.A., Medeiros, V.C., Nesi, J.R. 2006. Programa Geologia do Brasil -PGB. Projeto Geologia e Recursos Minerais do Estado do Rio Grande do Norte. Mapa geológico do Estado do Rio Grande do Norte. Escala. 1:500.000. Recife: CPRM/FAPERN, 2006. 1mapa color.

ARTHAUD, M. H. Evolução neoproterozóica do grupo Ceará (domínio Ceará central, NE Brasil): da sedimentação à colisão continental brasiliana. 170 f. Tese (Doutorado em Geociências)Universidade de Brasília, Brasília, 2007.

BRANDÃO, R.L. Sistema de Informação para Gestão e Administração Territorial da Região Metropolitana de Fortaleza Projeto SINFOR: Mapa Geológico da região Metropolitana de Fortaleza. Texto explicativo CPRM, 1995.

BRITO NEVES, B.B. América do Sul: quatro fusões, quatro fissões e o processo acrecionário andino. Bahia. VII Simpósio Nacional de Estudos Tectônicos, ANAIS SBG. 11-13.1999.

CASTRO, D.L. ; BEZERRA, F. H. R. ; CASTELO BRANCO, R.M.G. . Geophysical evidence of crustal-heterogeneity control of fault growth in the neocomian iguatu basin, ne brazil. Journal of South American Earth Sciences, v. 26: 271-285, 2008.

CASTRO, D.L: BEZERRA, F.H.R: SOUSA, M.O. L: FUCK, R.A.2012. Influence of Neoproterozoic tectonic fabric on the origin of the Potiguar Basin, northeastern Brazil and its links with West Africa based on gravity and magnetic data. Journal of Geodynamics, v. 54: 29-42, 2012.

CASTRO, H.S. Influência Litológica nos Relevos do Alto Curso do Rio Cauípe, Caucaia, Ce. Monografia (Bacharelado em Geografia)- UFC, Fortaleza, 2013.

CAVAlcante, J. C. et al. Mapa geológico do Estado do Ceará - Escala 1:500.000. MME/CPRM. 2003.

GOMES, H.A.; SANTOS, E.J. dos.Mapa Geológico do Estado de Pernambuco. In:Gomes, H. A. (org.) Geologia e Recursos Minerais do Estado de Pernambuco, Escala 1:500.000. CPRM, texto explicativo 198 p., mapas, Brasília, 2001

FETTER, A.H.; SCHMUS, W.R.V.; SANTOS, T.J.S.; NETO, J.N.N.; ARTHAUD, M.H. $4 U P b$ and Sm-Nd geochronological constraints on the crustal evolution and basement architecture of Ceará State, NW Borborema Province, NE Brazil: implications for the existence of the Paleoproterozoic Supercontinent “Atlantica”. Revista Brasileira de Geociências, São Paulo, v. 30, n. 1, p. 102-106, 2000.

MAGINI, C \& HACKSPACHER P.C. Geoquímica e ambiência tectônica do arco magmático de Pereiro, região NE da Província Borborema. Revista Brasileira de Geociências, v. 38: 336-355, 2008. 
MAIA, R. P.; BEZERRA, F. H. R.; Potiguar Basin: Diversity of Landscapes in the Brazilian Equatorial Margin. In: Landscapes and Landforms of Brazil. Vieira, B.C.; Salgado, A.A.R.; Santos, L.J.C (Editors) Springer, London, 2015

MAIA, R.P.; BEZERRA, F.H.R. Condicionamento estrutural do relevo no nordeste setentrional brasileiro. Mercator, Fortaleza, v. 13, n. 1, p. 127-141, jan./abr, 2014.

MAIA, R. P.; NASCIMENTO, A.M.L.; BEZERRA, F. H. R.; CASTRO, H.S.; MEIRELES, A.J.A.; ROTHIS, L.M. Geomorfologia do campo de inselbergues de Quixadá - NE do Brasil. Revista Brasileira de Geomorfologia, N16, Vol.2, 2015.

MAIA, R. P.; BETARD, F.; BEZERRA, F. H.; Geomorfologia do dos maciços de Portalegre em Martins - NE do Brasil: Inversão do relevo em analise. Sumetido a revista Brasileira de Geomorfologia, 2015.

NASCIMENTO, R.S.C; Petrologia dos Granitóides Brasilianos associados a zonas de cisalhamento Remígio-Pocinhos (PB). Dissertação de Mestrado, Programa de Pós-graduação em Geodinâmica e Geofísica. PPGG-UFRN, Natal, RN, 1998.

NOGUEIRA, J.F. Estrutura, geocronologia e alojamento dos batólitos de Quixadá, Quixeramobim e Senador Pompeu- Ceará Central. Tese (Doutorado em Geologia)- Instituto de Geociências e Ciências Exatas da Universidade Estadual Paulista. Rio Claro, 2004.

OLIVEIRA, R.G. Arcabouço geofísico, isostasia e causas do magmatismo Cenozóico da Província Borborema e de sua margem continental. Tese de Doutorado (Geodinâmica e Geofísica), 400p. Universidade Federal do Rio Grande do Norte, Natal, 2008.

PEULVAST, J. P.; CLAUDINO SALES, V. Stepped surfaces and Paleolandforms in the Northern Brasilian <Nordeste>: Constraints on models of morfotectonic evolution. Geomorphology, v. 3: 89-122, 2003.

WANDERLEY, A.A.; SANTOS, E.J.; FERREIRA, C.A.; SILVA Jr., J.M.F. Mapa Geológico e de Recursos Minerais do Estado da Paraíba, Escala 1:500.000. Texto explicativo e mapa, 2002.

Recebido em: 12/01/2017

Aceito para publicação em: 17/05/2017 